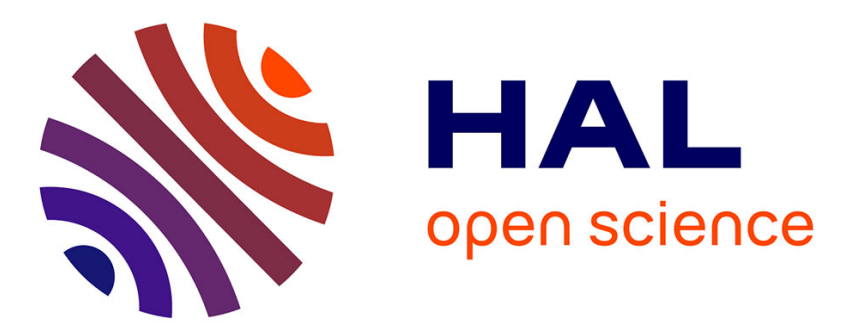

\title{
On the High Sensitivity of Corrosion Resistance of NiTi Stents with Respect to Inclusions: An Experimental Evidence
}

Fan Sun, Laurence Jordan, Valérie Albin, Virginie Lair, Armelle Ringuedé, Frédéric Prima

\section{To cite this version:}

Fan Sun, Laurence Jordan, Valérie Albin, Virginie Lair, Armelle Ringuedé, et al.. On the High Sensitivity of Corrosion Resistance of NiTi Stents with Respect to Inclusions: An Experimental Evidence. ACS Omega, 2020, 5, pp.3073 - 3079. 10.1021/acsomega.9b04312 . hal-03088617

\section{HAL Id: hal-03088617 https://hal.science/hal-03088617}

Submitted on 26 Dec 2020

HAL is a multi-disciplinary open access archive for the deposit and dissemination of scientific research documents, whether they are published or not. The documents may come from teaching and research institutions in France or abroad, or from public or private research centers.
L'archive ouverte pluridisciplinaire HAL, est destinée au dépôt et à la diffusion de documents scientifiques de niveau recherche, publiés ou non, émanant des établissements d'enseignement et de recherche français ou étrangers, des laboratoires publics ou privés. 


\title{
On the High Sensitivity of Corrosion Resistance of NiTi Stents with Respect to Inclusions: An Experimental Evidence
}

\author{
Fan Sun,* Laurence Jordan, Valérie Albin, Virginie Lair, Armelle Ringuedé, and Frédéric Prima
}

Cite This: ACS Omega 2020, 5, 3073-3079

Read Online

ABSTRACT: In this study, the electrochemical breakdown potentials $\left(E_{\mathrm{b}}\right)$ of $\mathrm{NiTi}$ stents were assessed in correlation to their nonmetallic inclusion fractions in the extra low inclusion (ELI) range (inclu.\% $<1 \%$ in area fraction, average size $<39 \mu \mathrm{m}$ ). Quantitative investigations were performed to study the role of nonmetallic inclusions during pitting corrosion. Two stent samples with different inclusion fractions were fabricated using commercial $\mathrm{NiTi}$ tubes for studying the corrosion and mechanism. A survey of seven commercial stents in Europe was also conducted. Dependence was observed between the breakdown potentials and the inclusion fractions in the ELI stent (inclu.\% $=0.2-0.8 \%$ ), in which the breakdown potentials were found to be inversely proportional

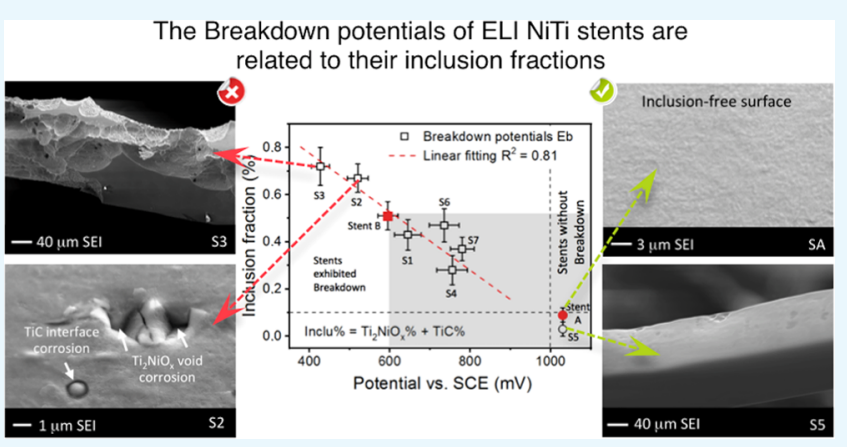
to inclusion fractions and densities $\left(E_{\mathrm{b}}\right.$ dropped from $\sim 800$ to $\left.\sim 400 \mathrm{mV}\right)$. No breakdown occurred on the samples using high-purity NiTi materials (inclu.\% $<0.1 \%$ ). The roles of inclusions in pitting mechanisms were investigated using scanning electron microscopy (SEM) characterizations. The microstructural evidence showed that the impact of $\mathrm{TiC}$ and $\mathrm{Ti}_{2} \mathrm{NiO}_{x}$ was very different in the pitting process. A maximum inclu.\% $\leq 0.9 \%$ was required for obtaining $E_{\mathrm{b}} \geq 600 \mathrm{mV}$ to meet the Food and Drug Administrations (FDA's) in vivo safety acceptance (low risk up to 6 months postimplantation). The high-purity stents (inclu.\% $<0.1 \%$ ) did not exhibit corrosion susceptibility until $1000 \mathrm{mV}$, suggesting superior corrosion resistance and thus long-term in vivo safety.

\section{INTRODUCTION}

The long-term safety of stents "in service" is the most important specification besides their mechanical functionality. It is well known that the environment of a stent in service is rather extreme, combining contact to corrosive body fluids and fatigue loading in vessels. This may endanger the long-term structural integrity of the devices, causing subsequent $\mathrm{Ni}$ release, early fracture, fatigue failure, and most of the postimplantation complications. ${ }^{1-4}$ Intrinsically, high-purity $\mathrm{NiTi}$ alloys, widely used as self-expandable stents, exhibit excellent biocompatibility and high corrosion resistance thanks to the protection of a uniform thin layer of $\mathrm{TiO}_{2}$ naturally formed on the surface. ${ }^{1}$ For biomedical applications, extensive research and highly restricted regulatory standards have been dedicated to understand and to guarantee the quality of the NiTi devices. ${ }^{2}$ Among these studies, corrosion and fatigue resistances are found to be the two main properties of highquality NiTi devices. It has been proven that the two properties are highly dependent on the device surface finishing and the nonmetallic inclusion fraction (oxides and/or carbides). Recent studies on fatigue resistance have clarified the role of nonmetallic inclusions in NiTi stents, showing that high-purity NiTi exhibited much superior medium- and highcycle fatigue resistance and highlighting the respective role of the nature, chemistry, size, and density of the inclusions in the degradation of fatigue performances. ${ }^{3}$ These inclusions are known to be due to interstitial impurities such as oxygen and carbon from raw materials and the ingot melting environment. ${ }^{4}$ The formation of oxides and carbides usually occurs after the solidification step of NiTi ingots. These inclusions, dispersed in the bulk material, are generally $\mathrm{Ti}_{2} \mathrm{NiO}_{x}$ and $\mathrm{TiC}$, displaying micrometric sizes. The area fraction, size, and density are the three parameters used to characterize the nonmetallic inclusions of NiTi devices. The American Society for Testing and Materials (ASTM) F $2063^{5}$ standard requires a maximum allowable fraction of $2.8 \%$ (area \%) and a dimension no larger than $39.0 \mu \mathrm{m} .{ }^{4}$ Aiming at improving the fatigue and corrosion resistance of stents in service, most stent producers have imposed stricter criteria on inclusions, limited to $1.0 \%$ in area fraction called extra low inclusion (ELI) and $12.9 \mu \mathrm{m}$ as a maximum size, for commercial products. ${ }^{6}$ However, the role of nonmetallic inclusions in the corrosion mechanism of $\mathrm{NiTi}$ stents was much less visited when compared to the studies on fatigue resistance and surface engineering. ${ }^{7-9}$ In the literature, corrosion assessments are usually performed without the quantification of inclusions on a NiTi plate or wire samples, on

Received: December 16, 2019

Accepted: January 28, 2020

Published: February 10, 2020 
which the corrosion resistance was found to be very sensitive to the surface finishing. ${ }^{10-12}$ As a consequence, the dependence could not be determined between breakdown potentials and inclusion fractions. Regarding the chemistry of the inclusions, Hwang et al. ${ }^{13}$ reported that the TiC inclusions could lead to a local galvanic coupling with the NiTi matrix since these particles were shown to be cathodic with respect to the matrix. As to NiTi stents, non-ELI (inclu.\% > 1\%), a statistical study performed by $\mathrm{M}$. Wohlschlögel et al. ${ }^{14}$ proved that the inclusion size could affect the corrosion susceptibility of electropolished NiTi stents, i.e., the larger the inclusion size, the lower the corrosion resistance. This work suggested that the inclusions and inclusion-induced defects (strings and voids) could act as sites and crevices during the potentiodynamic polarization test and subsequently lead to an electrochemical breakdown. However, no microstructural observations were provided to understand the role of inclusions (type, area fraction, or density) in the corrosion mechanisms. To clarify the role of inclusions and the related defects in corrosion susceptibility, the present work aims at investigating quantitatively the inclusion chemistry, fraction, size, and density and their influences on pitting damages.

We followed a two-fold strategy: (a) two "model" stents were fabricated that conformed to ASTM F86 ${ }^{15}$ surface finishing from fully characterized NiTi tubes involving two different vol \% of inclusions (both belonging to the so-called ELI class of Nitinol), and a first correlation between the inclusion fraction and corrosion resistance has been established; (b) a validation procedure of the established dependency is performed using seven different commercial stents (F86 finishing) with various inclusion fractions, confirming the drastic sensitivity of the corrosion behavior with respect to inclusions. The correlative study between the corrosion resistance and inclusions was aimed to clarify the susceptibility and mechanism of the inclusion-induced pitting corrosion in ELI NiTi stents.

\section{MATERIALS AND METHODS}

Stent Samples' Realization and Specifications. Two model stent samples (Stents A and B) were fabricated for this study using two different ELI NiTi tubes (Tubes A and B) compliant with the ASTM F2633-07 ${ }^{16}$ standard (nominal $\mathrm{Ni} 50.8$ atom \%, $500 \mathrm{~mm}$ in length, $2 \mathrm{~mm}$ in outer diameter, and $0.15 \mathrm{~mm}$ in wall thickness). The stent processing flow is shown in Figure S1.

The open-cell design was used to be common to commercial stents. The final stent samples were fully operational on selfexpansion after crimping to catheter size. The austenite finish (Af) temperature was set to $22 \pm 3{ }^{\circ} \mathrm{C}$. Tube B and Stent B were identical to Tube A and Stent A in sizes, designs, and surface finishing conforming to the ASTM F86 standard. ${ }^{15}$ For each sample, all of the specimens were cut from the same $\mathrm{NiTi}$ tube and were $25 \mathrm{~mm}$ in length and $6 \mathrm{~mm}$ in diameter. Eight specimens were selected for each sample lot after quality control of strut dimensions, uniformity, structural integrity, and surface finishing (ASTM F86 ${ }^{15}$ ). A thin protective $\mathrm{TiO}_{2}$ layer $(<10 \mathrm{~nm})$ was formed uniformly by the electropolishing process similar to the commercial stents.

The tube quality was examined for chemical compositions (energy-dispersive X-ray (EDX) microanalysis Princeton $\gamma$ tech PRISMIG at $15 \mathrm{kV}$ ), inclusions (ASTM E1245 ${ }^{17}$ on FEG scanning electron microscopy (SEM) Zeiss Leo 1530), geometry uniformity (Optical Keyence VHX-5000), mechan- ical properties (uniaxial tensile test INSTRON 5966), and phase transformation temperatures (differential scanning calorimetry (DSC) Mettler Toledo DSC822e).

Seven commercial NiTi stent samples from seven different providers (kept anonymous in the paper) were received in the final product form. They were produced in 2014-2016 for clinical use in European countries. These stents were similar in dimensions (6 $\mathrm{mm}$ in diameter, $160-190 \mu \mathrm{m}$ in strut thickness, 150-200 $\mathrm{mm}$ in length), using common designs and ASTM F86 ${ }^{15}$ surface finishing (electropolishing without coating). All seven stents were examined in the as-received state; micrographs are shown in the Supporting Information, denoted S1-S7 hereafter. The commercial samples were carefully cut into $\sim 25 \mathrm{~mm}$ long specimens (5-8 specimens per sample) for inclusion and corrosion studies. The Af temperature among the seven samples varied between 8.8 and 26.9 ${ }^{\circ} \mathrm{C}$.

Methods of Characterization. The ASTM E $1245^{17}$ practice was used to quantify the nonmetallic inclusions with backscatter electron imaging (BSI) at 1000×. The inclusion area fraction, size, and density were quantified by image analysis using Image J. ${ }^{18}$ Inclusion compositions were characterized by EDX spectroscopy in mapping and spot modes. Eighty random zones were imaged on each NiTi tube (mechanical polished) and 40 random zones per stent specimen (5-8 per sample) for inclusion quantification.

The ASTM F2129-17 ${ }^{19}$ protocol and standard instruments were used for corrosion susceptibility assessments of stent specimens. Rest potentials $\left(E_{\mathrm{r}}\right)$ of the specimens were measured by suspending the specimens in phosphate-buffered saline (PBS) under open-circuit conditions for $1 \mathrm{~h}$. The potential scan started from $E_{\mathrm{r}}$ toward the anodic direction at a constant rate of $1 \mathrm{mV} / \mathrm{s}$. The scan was reversed at the predetermined vertex potential $\left(E_{\mathrm{v}}\right)$ of $1000 \mathrm{mV} /$ saturated calomel electrode (SCE) or when the current thresholds reached two decades greater than the current recorded at breakdown $\left(E_{\mathrm{b}}\right)$. The mean values of $E_{\mathrm{r}}, E_{\mathrm{b}}$, and $E_{\mathrm{v}}$ were reported for each sample (5-8 tests per sample). The repeatability of this study was comparable to the E691 reference studies for the F2129 standard. ${ }^{19}$ After the electrochemical tests, the samples were cleaned with distilled water and ethanol for postcorrosion SEM analysis.

\section{RESULTS AND DISCUSSION}

Quantification and Microanalysis of Nonmetallic Inclusions. The inclusions in the minitubes generally resulted from the raw ingot impurities; then, subsequent inclusionrelated defects were due to the microextrusion process. These inclusions were distributed homogeneously in the specimens. Micrographs of the tubes and stent samples are shown in Figure 1. The inclusions and microstructural defects of the two NiTi tubes (Tubes A and B) were compared; two example images are shown in Figure 1a. Similar stringlike defects (composed of inclusion fragments and voids) and inclusions could be seen on the outer surfaces (the surface that is not affected by the laser cutting process). These defects were due to the microextrusion process, during which the inclusions rotated and fragmented in traces along the tubing axis. As a result, these strings were always parallel to each other. Most of the inclusions were accompanied by tubing strings longer in the case of $\mathrm{Ti}_{2} \mathrm{NiO}_{x}$ fragments (could reach $10 \mu \mathrm{m}$ ) and shorter in the case of $\mathrm{TiC}$ (about several microns). 
(a)

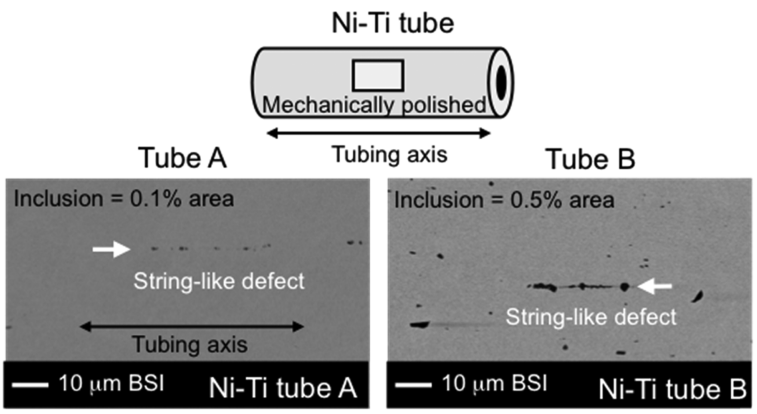

(b)

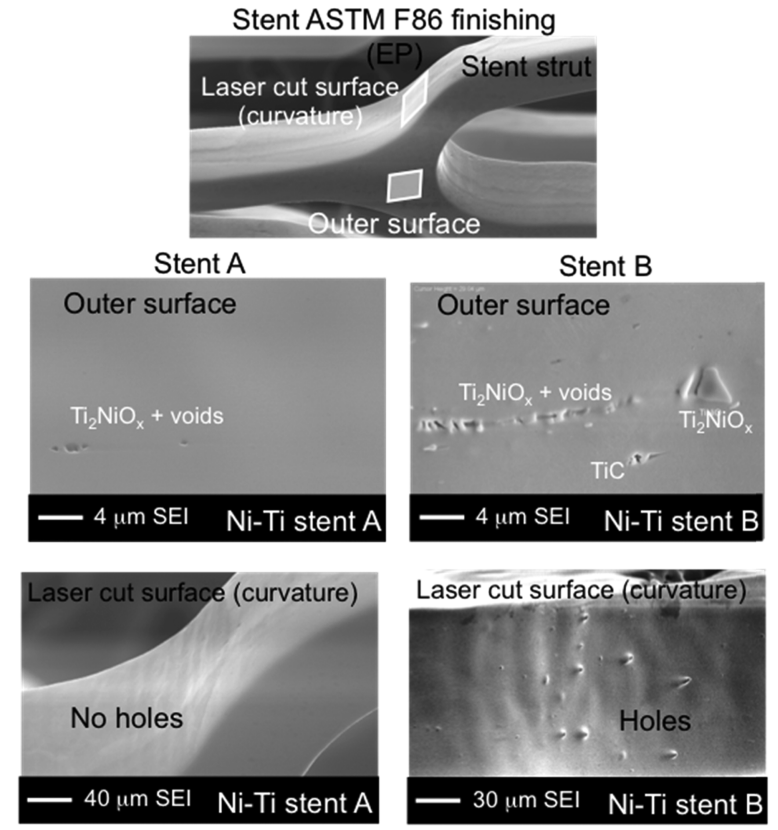

Figure 1. (a) SEM micrographs of the outer surfaces of tubes A and B after mechanical polishing; (b) SEM micrographs of the inclusions on Stents A and B (BSI: backscatter imaging; SEI: secondary electron imaging).

On quantification, Tube A presented an inclusion fraction around 0.1 area\% and Tube B presented 0.5 area\% (Figure 1a). The two tubes were compliant with the ELI grade. The stent samples fabricated from the two tubes inherited the inclusions and defects from the microtubes. The laser-cut process generated new surfaces in the thickness of the strut. These new surfaces were defaulted with prior internal inclusions of the microtube, cutting the stringlike defects in a nonparallel direction (Figure 1b). As a result, additional inclusions and defects in the tube volume could be exposed on the laser-cut surfaces. The defects in the form of holes could be produced when the laser-cut surfaces intersected inclusion strings (as shown on Stent B in Figure 1b). Therefore, the density of holes was associated with the inclusion fractions, i.e., no hole was observed on Stent A (inclu.\% = 0.1\%), whereas few holes were observed on Stent B (inclu.\%=0.5\%). It is worth noting that the electropolishing process (ASTM F86 ${ }^{15}$ ) is not able to eliminate either the inclusions or the associated holes induced by inclusions.

One sample of Tube B is presented in Figure 2 to show the results of the quantification and microanalysis of the inclusions conforming to the ASTM E $1245^{17}$ standard. Figure 2a presents the BSI micrograph on the polished surface, on which the inclusions and defects stood out due to the contrast of the material density, i.e., the inclusions (oxides and carbides) and voids were less dense than the NiTi matrix. The total area fraction of the inclusions (and voids) at the imaged area was $0.5 \%$. Image posttreatment (by Image ${ }^{18}$ ) could then isolate the inclusions for statistics. EDX microanalysis results (Figure 2b) showed the differences between the two types of inclusions, oxide $\left(\mathrm{Ti}_{2} \mathrm{NiO}_{x}\right)$ and carbide $(\mathrm{TiC})$, using element mapping and quantitative spectroscopy. It can be noticed that the oxide inclusion was broken into continuous fragments and voids in a string, whereas the carbides were still in one piece with small voids.

Corrosion Susceptibility of All Samples. Corrosion susceptibility assessments (F2129-17 ${ }^{19}$ ) were repeated on the eight specimens of Stents A and B, respectively. Figure 3 presents two typical examples of the cyclic polarization curves (ASTM F $2129^{19}$ ) of Stent A (inclu.\% = 0.1\%) and Stent B (inclu.\% $=0.5 \%$ ). No breakdown occurred on any of the Stent A specimens before reaching the vertex potential $\left(E_{\mathrm{v}}=1000\right.$ $\mathrm{mV})$. However, breakdown $\left(E_{\mathrm{b}}\right)$ occurred on Stent B in a reproducible manner on all eight specimens at about $600 \mathrm{mV}$ during positive scanning.

The above results demonstrated a clear dependence between the inclusion density and corrosion resistance in the model stents. It can be noticed that even in the ELI range, the corrosion resistance may be strongly impacted by the inclusion-related defects. To confirm the established dependence, a study on inclusions and corrosion resistance was then performed on seven different commercial stent samples from different providers (the same surface finishing as the model stents, shown in Figure S2). The summary statistical results from the 5-8 specimens of each sample are shown in Figure 4 ( $4 \mathrm{a}$ for inclusion, $4 \mathrm{~b}$ for corrosion). It can be noticed that the samples were all of ELI grade but the inclusion fractions of different samples showed large differences from $0.03 \%$ (S5) to $0.72 \%$ (S3). Several points are also worth mentioning: (a) compared to Tubes A and B, Stents A and B seemed to present a slight reduction of inclusion fractions, but the differences were in the magnitude of measurement error; (b) the inclusions could be present as a single type (oxides or carbides) or mixed types; and (c) in the samples with mixed inclusions, the ratios between oxide and carbide were also different from one another.

Figure $4 \mathrm{~b}$ summarizes the results of $\mathrm{F} 2129^{19}$ assessments of all of the stent samples. The standard deviations of the measurements of the stent samples were close to the ASTM (the first two columns) studies. ${ }^{19}$ The correlative plotting between the inclusion fractions and the breakdown potentials is shown in Figure 4c. It can be noticed that the correlation between the inclusion fraction and $E_{\mathrm{b}}$ seems to be almost linear in the ELI range. A linear fit $\left(R^{2}=0.81\right)$ was roughly associated with the inclu.\% vs $E_{\mathrm{b}}$ in the range $400 \mathrm{mV}<E_{\mathrm{b}}<$ $800 \mathrm{mV}$. In a recent study, the US Food and Drug Administration (FDA) reported that the F2129 safety acceptance was $E_{\mathrm{b}} \geq 600 \mathrm{mV}$ for $\mathrm{NiTi}$ stents in an in vivo environment for 6 months postimplantation without pitting corrosion risk. ${ }^{20}$ So, the shadow square (in the background) indicates the in vivo safety area by considering this criterion. Regarding this FDA acceptance based on Rosenbloom and Corbett, ${ }^{21}$ samples including S2, S3, and Stent B could be risky with respect to pitting corrosion during the first 6 months after stent implantation.

Investigation of Pitting Damages Initiated at the Defects (Inclusions and Holes). A summary of the inclusion-related corrosion damages after $\mathrm{F} 2129^{19}$ assessments 
(a)
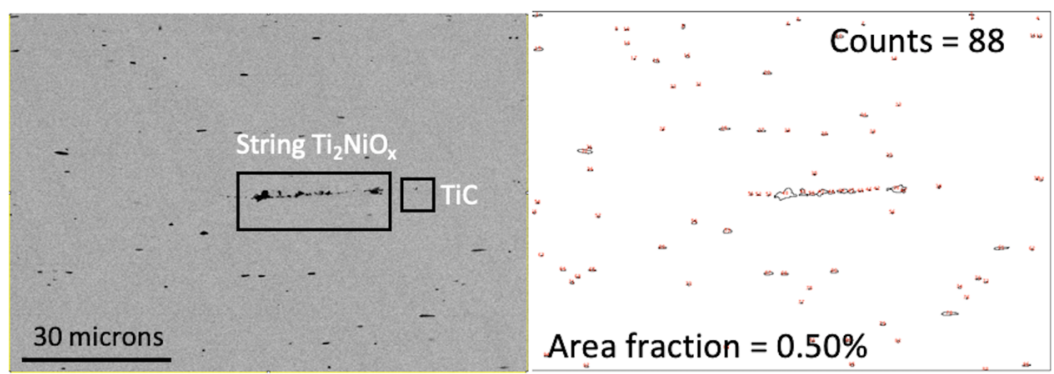

(b)
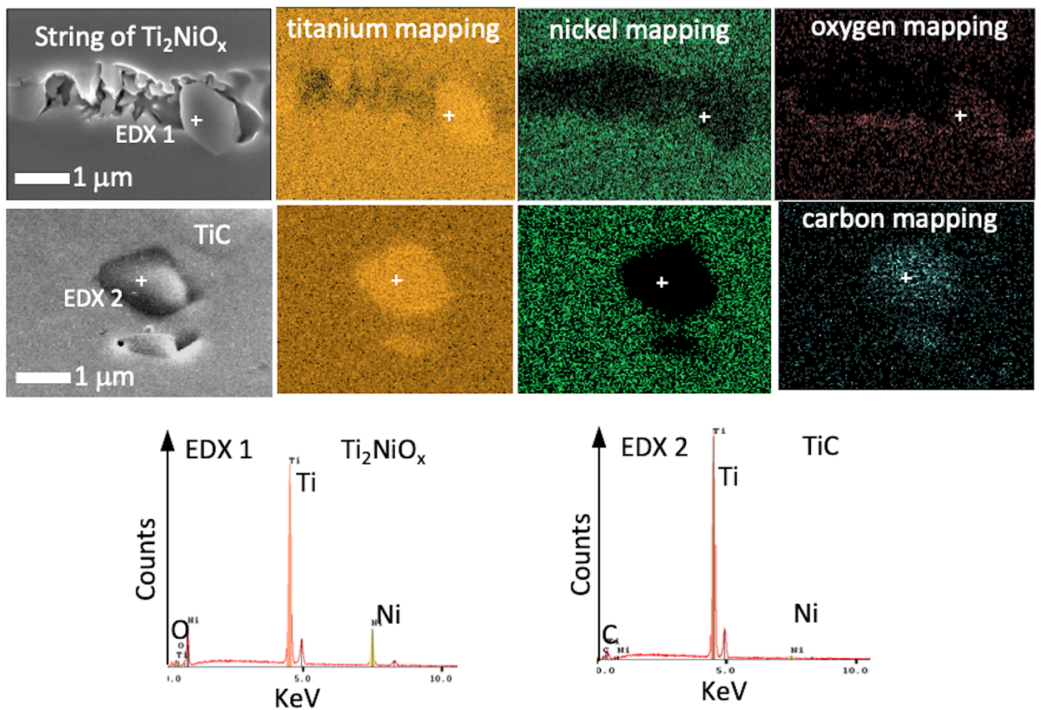

Figure 2. Tube B (a) SEM BSI at 1000× magnification and postanalysis of particles by ImageJ software. (b) EDX microanalysis (Ti, yellow; Ni, green; $\mathrm{O}$, red; and $\mathrm{C}$, cyan) of an inclusion string $\left(\mathrm{Ti}_{2} \mathrm{NiO}_{x}\right)$ and an individual inclusion $(\mathrm{TiC})$ by element mapping and quantitative spectroscopy.

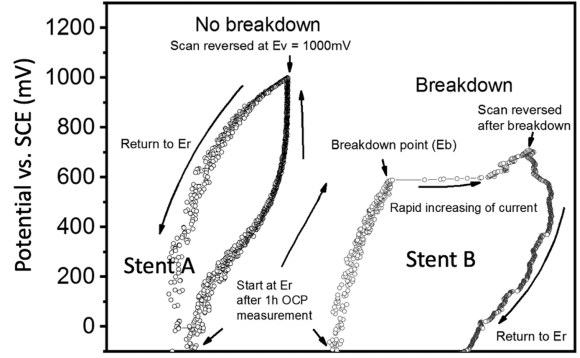

Log current density $\left(\mathrm{mA} / \mathrm{cm}^{2}\right)$

Figure 3. Cyclic polarization curves of one specimen of Stent A (inclu. $\%=0.1 \%$ ) and one specimen of Stent B (inclu. $\%=0.5 \%$ ).

(of all of the stent samples) is shown in Figure 5. The corrosion sites were especially observed to investigate the responses of inclusions to the potentiodynamic polarization.

In the cases of the $\mathrm{Ti}_{2} \mathrm{NiO}_{x}$ string (as shown in Figure 5a,b), the pitting corrosion could probably initiate at the voids of the string and penetrated into the NiTi matrix, causing alloy dissolution in the corrosion pits. The oxide particles/interfaces seemed to be less involved in the corrosion process (intact until the collapse of the strut surface, as shown in Figure $5 b)$. In the cases of $\mathrm{TiC}$ (Figure 5c), both the interfaces ( $\mathrm{TiC} /$ $\mathrm{NiTi}$ ) and voids were active with respect to the pitting process, finished by forming an open pitting hole (Figure $5 \mathrm{~d}$ ), where the $\mathrm{TiC}$ inclusion remained at the bottom of the cavity. It is worth mentioning that in Figure 5d, a $\mathrm{TiC}$ inclusion could be seen on the pit wall. It was an inclusion beneath the strut surface but exposed to an electrolyte due to the coarsening of the corrosion pit. It could probably be able to further enhance the pitting process. In the cases of adjacent $\mathrm{Ti}_{2} \mathrm{NiO}_{x}$ and $\mathrm{TiC}$ (Figure 5e,f), corrosion could probably occur simultaneously at the voids and the $\mathrm{TiC}$ interfaces, developing to a pitting site as observed in Figure $5 \mathrm{f}$. In the cases of an inclusion-free surface (Figure $5 \mathrm{~g}$ from sample S5), no pitting was observed, with only a slight increase of the surface roughness when compared to the surface before the corrosion test (Figure S2e). Moreover, Figure $5 \mathrm{~h}$ presents a typical corrosion pit surface, on which inclusions and structural defects in the strut volume were revealed.

Postcorrosion investigations were also dedicated to the holes on the laser-cut surfaces. Figure 6 presents the comparison before (Figure 6a,b) and after corrosion (Figure $6 c, d$ ) at the same location. The holes at the bottom of the U-shaped strut initiated the pitting corrosion. Thus, the strut could probably be corroded simultaneously from both the outer surface and laser-cut surfaces, on which the holes could act as confined crevices for corrosion. The micrographs after corrosion tests of all of the commercial stent samples are shown in Figure S3.

The above results could indicate correlations between corrosion resistance and inclusions in NiTi stents. The differences in inclusion types and fractions could have been induced by raw materials from different suppliers using 
(a)

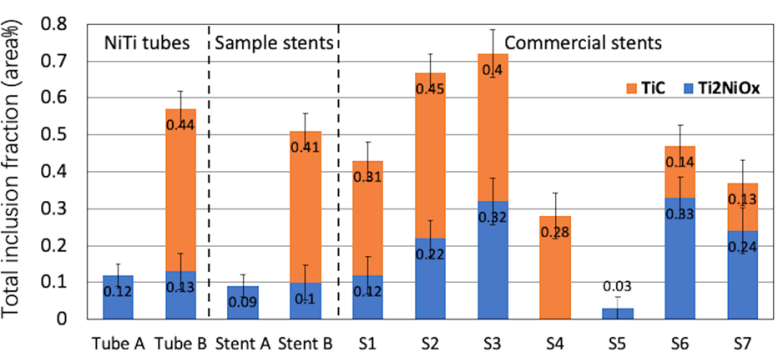

(b)

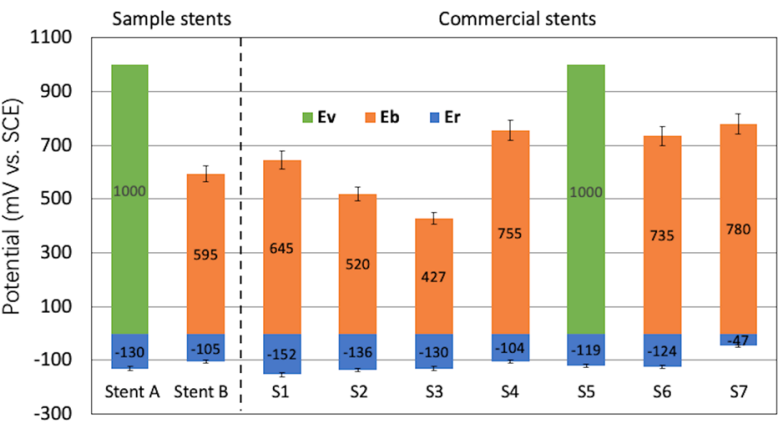

(c)

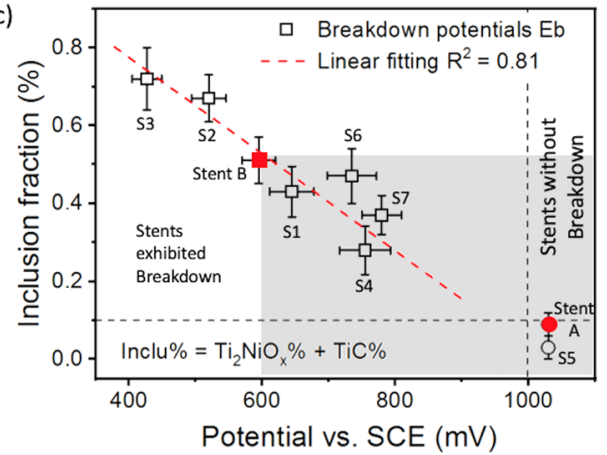

Figure 4. Summary of inclusion fractions and breakdown potentials $\left(E_{\mathrm{b}}\right)$ of the samples (tubes $\mathrm{A}$ and $\mathrm{B}$, Stents $\mathrm{A}$ and $\mathrm{B}$, and seven commercial stents $\mathrm{S} 1-\mathrm{S} 7$ ). (a) Total inclusion fraction, $\mathrm{Ti}_{2} \mathrm{NiO}_{x}$ fraction (blue), and $\mathrm{TiC}$ fraction (orange). (b) Polarization potentials $\left(E_{\mathrm{r}}\right.$, blue; $E_{\mathrm{b}}$, orange; and $E_{\mathrm{v}}$, green). (c) Plot correlating the total inclusion fractions ( $y$-axis) to breakdown potentials ( $x$-axis) of the samples that exhibited breakdown during polarization tests (marked by squares; Stent B is highlighted in red). Stent A is highlighted in red, and the samples without breakdown are plotted at the bottom right corner beyond $E_{\mathrm{v}}(1000 \mathrm{mV})$ and marked by circles.

different elaboration techniques. In the previous studies, the oxide and carbide inclusions had been suggested to be almost neutral to corrosion resistance on annealed ingots without deformation. $^{12}$ Indeed, the electrochemistry nature of the $\mathrm{Ti}_{2} \mathrm{NiO}_{x}$ was supposed to be similar to the $\mathrm{TiO}_{2}{ }^{12,1312,13}$ and $\mathrm{TiC}$ particles were, even cathodic to NiTi matrix, ${ }^{14}$ but not enough in cathode/anode surface ratio to trigger the pitting corrosion via galvanic-like coupling. Nevertheless, the situation could be different when considering the structural defects related to $\mathrm{Ti}_{2} \mathrm{NiO}_{x}$ after tubing deformation. The oxides could break into fragments and rotate in distance by leaving strings and voids. As a consequence, the size of the inclusion reduced but the length of the inclusion strings increased. As observed in this study, the length of the strings could reach several tens of microns (the strut thickness was 160-190 $\mu \mathrm{m}$ ). After tube drawing, the original crystallographic interfaces (created by a diffusion- or interface-controlled precipitation process ${ }^{22}$ ) between the inclusion and the NiTi matrix were destroyed.
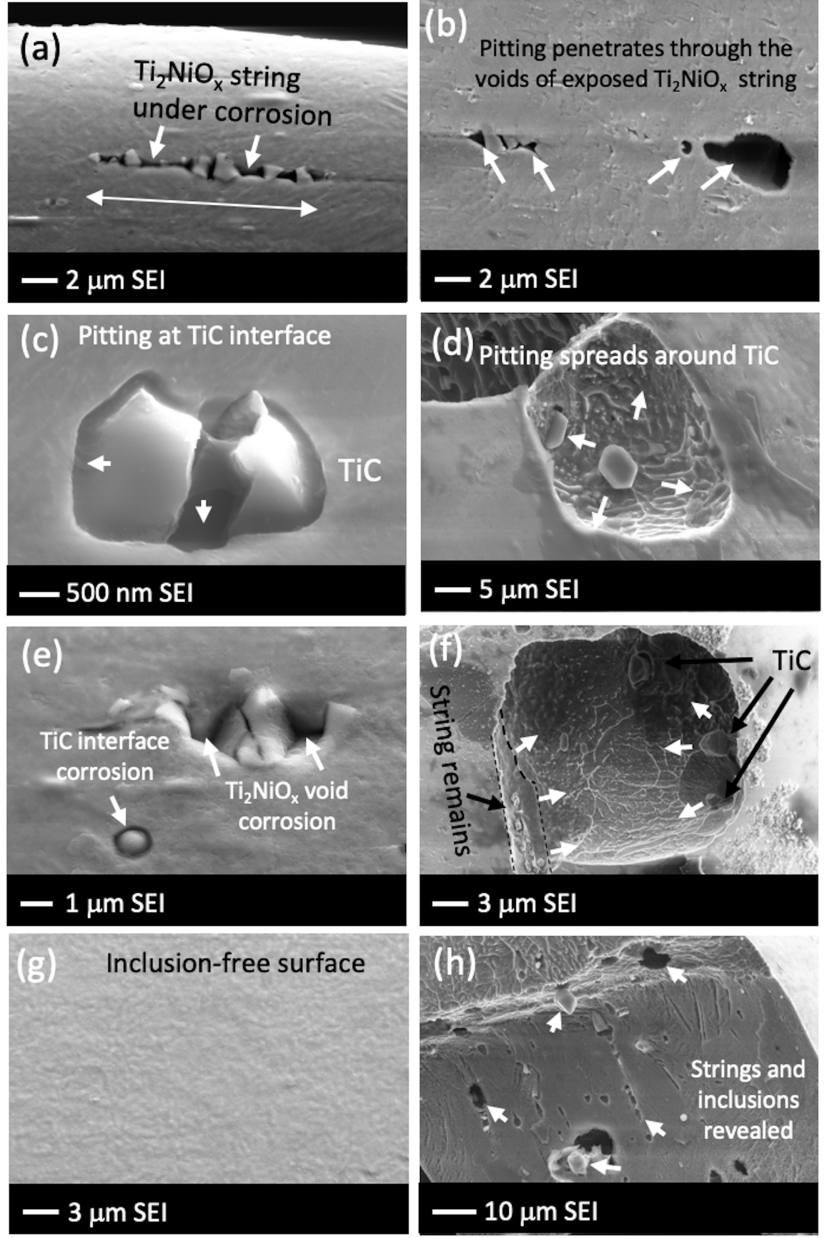

Figure 5. Summary of typical inclusions and related defects observed in all of the samples in localized pitting corrosion processes during polarization: ( $\mathrm{a}, \mathrm{b}$ ) behaviors of $\mathrm{Ti}_{2} \mathrm{NiO}_{x}$ strings; (c, d) behaviors of TiC inclusions; (e, f) behaviors of neighboring $\mathrm{Ti}_{2} \mathrm{NiO}_{x}$ strings and $\mathrm{TiC}$ inclusions; (g) surface without inclusions; and (h) fracture surface of a strut losing integrity.
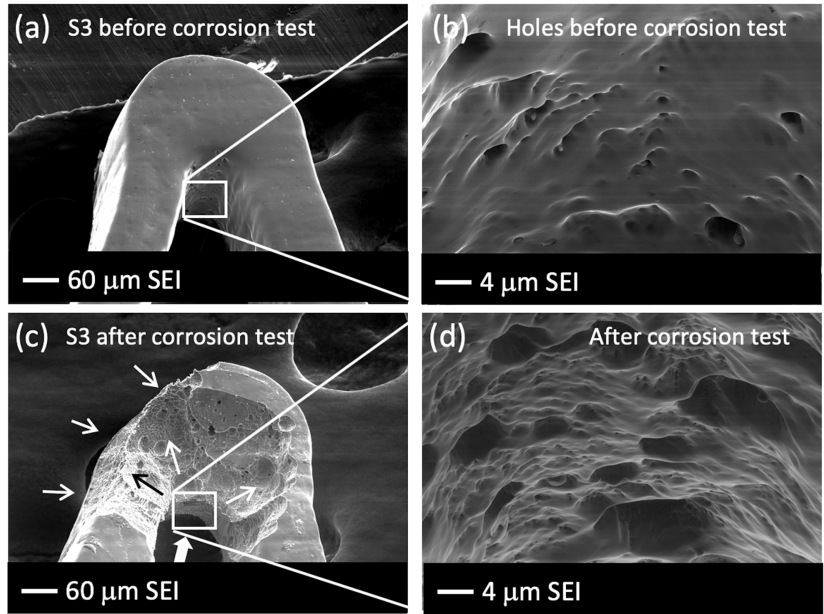

Figure 6. Investigations of pitting damages of sample S3 from the defects of holes: (a, b) surface finishing and defects before polarization tests; (c, d) specimen corroded at inclusion holes during the polarization tests.

From the observations on $\mathrm{Ti}_{2} \mathrm{NiO}_{x}$ strings (Figure 5a,b,e), the oxide interfaces showed good resistance to corrosion as 
suggested in the literature ${ }^{12}$ but the voids seemed very active to initiate pitting. It could be suggested that the voids in the strings served as crevices for corrosion in a confined space, where a small volume of the corrosive solution became stagnant, leading to oxygen depletion and eventually a halt in the oxygen reduction necessary for repassivation. ${ }^{23}$ Moreover, a similar situation could be assumed for the holes on the lasercut surfaces. The corrosion mechanisms of the two inclusion types could be very different: (a) $\mathrm{Ti}_{2} \mathrm{NiO}_{x}$-induced corrosion initiated on $\mathrm{Ti}_{2} \mathrm{NiO}_{x}$-associated defects, i.e., string voids and holes, while the interface between oxide and the NiTi matrix seemed to be inert; (b) TiC-induced corrosion initiated on both $\mathrm{TiC} / \mathrm{NiTi}$ interfaces and $\mathrm{TiC}$-associated defects. It may be suggested that, at the same area fraction, $\mathrm{TiC}$ inclusions could be more efficient than $\mathrm{Ti}_{2} \mathrm{NiO}_{x}$ regarding the initiation of pitting corrosion.

The inclusion size and density were important characteristics for a given inclusion fraction. The role of inclusion size in corrosion susceptibility has been reported, showing that the corrosion resistance increased as the size decreased from 15 to $8 \mu \mathrm{m} .{ }^{14}$ Then, the resistance started to decrease when the inclusion size became smaller than $8 \mu \mathrm{m} .{ }^{14}$ To clarify the inclusion size effect in that range (about $1-6 \mu \mathrm{m}$ in stents), breakdown potentials measured in this study were plotted as a function of inclusion size (Figure 7 ). It was found that the

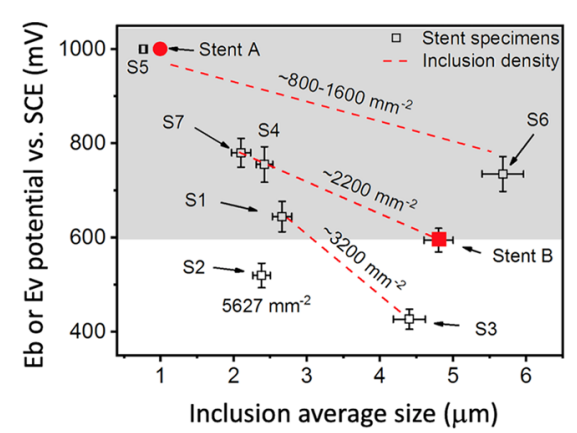

Figure 7. Plot of breakdown potentials in correlation to average inclusion sizes and inclusion densities. Red dashed lines represent the iso-density for $\leq 1600, \sim 2200$, and $\sim 3200 \mathrm{~mm}^{-2}$. The shadow square indicates the in vivo safety area $\left(E_{\mathrm{b}} \geq 600 \mathrm{mV}\right)$.

breakdown potentials showed an always-negative dependence on the inclusion size but the slope of the negative dependence was clearly related to the inclusion density. Several iso-density lines are drawn in Figure 7 (red dashed lines for $\leq 1600$, $\sim 2200$, and $\sim 3200 \mathrm{~mm}^{-2}$ ). The slopes increased when the densities increased from 1600 to $3200 \mathrm{~mm}^{-2}$. It would be reasonable to explain this density dependence by the fact that the total interface areas of the inclusions and inclusion-induced defects rapidly increased with density.

\section{CONCLUSIONS}

In this study, the electrochemical breakdown potentials $\left(E_{\mathrm{b}}\right)$ were assessed on ELI stent samples (inclusion fraction $<1$ area $\%)$. Two groups of samples are studied in comparison: the first group contains stent samples fabricated in the laboratory using two different NiTi tubes on inclusion fractions; the second group is composed of seven commercial stents with the same surface finishing. The results presented a noteworthy correlation between the nonmetallic inclusion fractions and the electrochemical breakdown potentials in the extra low inclusion range. A negative dependence was observed between the breakdown potentials and the inclusion fractions in the ELI stents (inclu.\% $=0.2-0.8 \%$ ), in which the breakdown potentials were found to be inversely proportional to inclusion fractions and densities $\left(E_{\mathrm{b}}\right.$ decreased from $\sim 800$ to $\sim 400 \mathrm{mV}$ ). No breakdown occurred on the samples using high-purity NiTi materials (inclu. $\%<0.1 \%$ ). The microstructural evidence showed that the effectiveness of $\mathrm{TiC}$ and that of $\mathrm{Ti}_{2} \mathrm{NiO}_{x}$ was very different in the pitting process. The maximum inclu. $\% \leq$ $0.9 \%$ was found to obtain $E_{\mathrm{b}} \geq 600 \mathrm{mV}$, the FDA's in vivo safety acceptance (low risk up to 6 months postimplantation). The high-purity stents did not exhibit corrosion susceptibility until $1000 \mathrm{mV}$, suggesting superior corrosion resistance and thus long-term in vivo safety.

\section{ASSOCIATED CONTENT}

\section{SI Supporting Information}

The Supporting Information is available free of charge at https://pubs.acs.org/doi/10.1021/acsomega.9b04312.

Figure S1, stent fabrication flow and a photograph of the as-received Tube A and the final stent; Figure S2, SEM and SEI micrographs of the struts of commercial stents S1-S7; and Figure S3, SEM and SEI images of the corrosion damages induced by polarization tests on commercial stents S1-S7 (PDF)

\section{AUTHOR INFORMATION}

\section{Corresponding Author}

Fan Sun - Chimie ParisTech, PSL University, CNRS, Institut de Recherche de Chimie Paris, 75005 Paris, France; 이이.org/ 0000-0002-4669-121X; Email: fan.sun@ chimieparistech.psl.eu

\section{Authors}

Laurence Jordan - Chimie ParisTech, PSL University, CNRS, Institut de Recherche de Chimie Paris, 75005 Paris, France; University Paris Diderot, Sorbonne Paris Cité, Paris F-75013, France; AP-HP, Hospital Rothschild, Paris F-75012, France

Valérie Albin - Chimie ParisTech, PSL University, CNRS, Institut de Recherche de Chimie Paris, 75005 Paris, France

Virginie Lair - Chimie ParisTech, PSL University, CNRS, Institut de Recherche de Chimie Paris, 75005 Paris, France

Armelle Ringuedé - Chimie ParisTech, PSL University, CNRS, Institut de Recherche de Chimie Paris, 75005 Paris, France

Frédéric Prima - Chimie ParisTech, PSL University, CNRS, Institut de Recherche de Chimie Paris, 75005 Paris, France

Complete contact information is available at:

https://pubs.acs.org/10.1021/acsomega.9b04312

\section{Notes}

The authors declare no competing financial interest.

\section{ACKNOWLEDGMENTS}

This study was supported by the interlaboratory collaboration between the Group of Structural Metallurgy (MS) and the Group of Interfaces, Electrochemistry, Energy (I2E).

\section{REFERENCES}

(1) Stoeckel, D.; Pelton, A. R.; Duerig, T. Self-expanding Nitinol stents - material and design considerations. Eur. Radiol. 2004, 14, 292-301. 
(2) Nagaraja, S.; Sullivan, S. J. L.; Stafford, P. R.; Lucas, A. D.; Malkin, E. Impact of nitinol stent surface processing on in-vivo nickel release and biological response. Acta Biomater. 2018, 72, 424-433.

(3) Robertson, S. W.; Launey, M.; Shelley, O.; Ong, I.; Vien, L.; Senthilnathan, K.; Saffari, P.; Schlegel, S.; Pelton, A. R. A statistical approach to understand the role of inclusions on the fatigue resistance of superelastic Nitinol wire and tubing. J. Mech. Behav. Biomed. Mater. 2015, 51, 119-131.

(4) Mwangi, J. W.; Nguyen, L. T.; Bui, V. D.; Berger, T.; Zeidler, H.; Schubert, A. Nitinol manufacturing and micromachining: a review of processes and their suitability in processing medical-grade Nitinol. J. Manuf. Processes 2019, 38, 355-369.

(5) ASTM F2063-12 Standard Specification for Wrought NickelTitanium Shape Memory Alloys for Medical Devices and Surgical Implants; ASTM International: West Conshohocken, PA, 2012; www. astm.org.

(6) Shabalovskaya, S.; Anderegg, J.; Van Humbeeck, J. Recent observations of particulates in Nitinol. Mater. Sci. Eng. A 2008, 481482, 431-436.

(7) Paprottka, K. J.; Paprottka, P. M.; Reiser, M. F.; Waggershauser, T. Comparative study of the corrosion behavior of peripheral stents in an accelerated corrosion model: experimental in vitro study of 28 metallic vascular endoprostheses. Diagn. Interv. Radiol. 2015, 21, 403-409.

(8) Shabalovskaya, S.; Anderegg, J.; Van Humbeeck, J. Critical overview of Nitinol surfaces and their modifications for medical applications. Acta Biomater. 2008, 4, 447-467.

(9) Vojtěch, D.; Voderova, M.; Kubasek, J.; Novak, P.; Seda, P.; Michalcova, A.; Fojt, J.; Hanus, J.; Mestek, O. Effects of short-time heat treatment and subsequent chemical surface treatment on the mechanical properties, low-cycle fatigue behavior and corrosion resistance of a $\mathrm{Ni}-\mathrm{Ti}(50.9$ at.\% $\mathrm{Ni}$ ) biomedical alloy wire used for the manufacture of stents. Mater. Sci. Eng. A 2011, 528, 1864-1876. (10) Kim, J.; Park, J.-K.; Kim, H. K.; Unnithan, A. R.; Kim, C. S.; Park, C. H. Optimization of electropolishing on NiTi alloy stents and its influence on corrosion behavior. J. Nanosci. Nanotechnol. 2017, 17, 2333-2339.

(11) Trépanier, C.; Tabrizian, M.; Yahia, L’H.; Bilodeau, L.; Piron, D. L. Effect of modification of oxide layer on NiTi stent corrosion resistance. J. Biomed. Mater. Res. 1998, 43, 433-440.

(12) Tuissi, A.; Rondelli, G.; Bassani, P. Plasma Arc melting (PAM) and corrosion resistance of pure NiTi shape memory alloys. Shape Mem. Superlastic. 2015, 1, 50-57.

(13) Hwang, W. S.; Kim, K. J.; Seo, W. C. In Pitting Corrosion of NiTi Shape Memory Alloy in Deaerated Chloride Solution, In 3th International Corrosion Congress, NACE International: Houston, TX, 1994, Paper No. 381.

(14) Wohlschlögel, M.; Steegmüller, R.; Schüssler, A. Potentiodynamic polarization study on electropolished nitinol vascular implants. J. Biomed. Mater. Res., Part B 2012, 100B, 2231-2238.

(15) ASTM F86-13 Standard Practice for Surface Preparation and Marking of Metallic Surgical Implants; ASTM International: West Conshohocken, PA, 2013, www.astm.org.

(16) ASTM F2633-13 Standard Specification for Wrought Seamless Nickel-Titanium Shape Memory Alloy Tube for Medical Devices and Surgical Implants; ASTM International: West Conshohocken, PA, 2013, www.astm.org.

(17) ASTM E1245-03 (2016) Standard Practice for Determining the Inclusion or Second-Phase Constituent Content of Metals by Automatic Image Analysis; ASTM International: West Conshohocken, PA, 2016, www.astm.org.

(18) Rasband, W. S. ImageJ; U.S. National Institutes of Health: Bethesda, MD, 1997-2016, http://imagej.nih.gov/ij/.

(19) ASTM F2129-17 Standard Test Method for Conducting Cyclic Potentiodynamic Polarization. Measurements to Determine the Corrosion Susceptibility of Small Implant Devices; ASTM International: West Conshohocken, PA, 2017, www.astm.org.

(20) Nagaraja, S.; Di Prima, M.; Saylor, D.; Takai, E. Current practices in corrosion, surface characterization, and nickel leach testing of cardiovascular metallic implants. J. Biomed. Mater. Res., Part B 2017, 105, 1330-1341.

(21) Rosenbloom, S. N.; Corbett, R. A. In An Assessment of ASTM F 2129 Test Results Comparing Nitinol to Other Implant Alloys, Proceedings of the International Conference on Shape Memory and Superelastic Technologies, ASM International: Pacific Grove, CA, 2006; pp 243-252.

(22) Nishida, M.; Wayman, C. M.; Honma, T. Precipitation processes in near-equiatomic TiNi shape memory alloys. Metall. Trans. A 1986, 17A, 1505-1515.

(23) Halwani, D. O.; Anderson, P. G.; Brott, B. C.; Anayiotos, A. S.; Lemons, J. E. Clinical device-related article surface characterization of explanted endovascular stents: evidence of in vivo corrosion. J. Biomed. Mater. Res., Part B 2010, 95B, 225-238. 